\title{
Experimental analysis of the stability of ferrofluids based on Iron Oxide powder
}

\author{
Daniel ZĄBEK ${ }^{1}$, Andrzej GRZEBIELEC ${ }^{* 1}$, Luca CMOK $^{2}$, Patricija HRIBAR BOŠTJANČIČ², \\ and Alenka MERTELJ ${ }^{2}$ \\ ${ }^{1}$ Faculty of Power and Aeronautical Engineering, Warsaw University of Technology, Warsaw, Poland \\ ${ }^{2}$ Department of Complex Matter, Jožef Stefan Institute, Ljubljana, Slovenia
}

\begin{abstract}
Ferrofluids most often consist of three components, they are: solid particles, the liquid in which they are dissolved and a substance that is supposed to prevent sedimentation - called surfacant. The biggest problem with ferrofluids is their stability. Mixtures in which one of the phases is a solid phase have a natural tendency to sedimentation. As a result, physical properties change during the use of such materials. As part of the research, it was decided to check which ferrofluid composition would be most resistant to continuous evaporation and condensation processes. Three different mixtures were analyzed. As a result of the experiment it was found that the best behavior was mixture of: iron-oxide with n-heptane and fatty acid as surfacant.
\end{abstract}

Keywords: ferrofluids, stability, energy efficiency

\section{Introduction}

Heat and mass transfer phenomena is becoming the limiting factor of modern electrical components (e.g. CPUs, solid state memory), energy transformation (e.g. rectifiers and inverters), energy generation (e.g. fuel cells) and energy storage technologies (e.g. batteries). In these fields, extreme thermal loads of up to $1 \mathrm{~kW} \cdot \mathrm{cm}^{-2}$ are expected and therefore, a need for an immediate breakthrough in cooling technology research has been identified [12]. One promising approach to resolve these limitations is the use of ferrofluids. Ferrofluids have, compared to pure solvents or water, solid ferromagnetic particles dispersed in a liquid carrier fluid. The dispersed particles can change the rheology and heat transfer properties of the fluid and can be used for various applications such as e. g. in magnetic transformer oil for electrical insulation and cooling [13], in lubrication and establishing thermal contact in shaft bearings in turbines, [21] as seals and for damping [22]. One particular advantage with ferrofluids is that the solid ferromagnetic particles dispersed in thecarrier fluid usually have a high thermal conductivity compared to the base liquid carrier fluid [19]. However, in ferrofluids the interaction between the solid particles dispersed in the liquid carrier fluids critical to the ferrofluid mixture. In order to prevent particle agglomeration and to maintain a repelling force between the particles, the particles must be coated with a stabilizing dispersing agent, also referred to as a surfactant. The surfactant are molecules which modify the surface properties of the ferromagnetic particles in order to obtain a stable suspension or colloid [20]. The repelling force between the particles is maintained despite strong magnetic fields or high temperatures. However, under high temperatures the liquid carrier fluid experiences boiling. This boiling phase transition is complex because it separates the solid particles from the gaseous. On the other hand, this phase transition can be favourable because the evaporation process has the potential to be much more effective than conventional thermal conductivity, due to the high level of thermal energy needed for evaporation. The possibility to cycle the ferromagnetic particles through an evaporation and condensation phase is primarily dependent on the surfactant maintaining the repelling force between the solid particles.

\footnotetext{
*Corresponding author: E-mail address: (andrzej.grzebielec@pw.edu.pl) Andrzej GRZEBIELEC
} 


\section{Experimental procedure}

Three different classes of $\mathrm{Fe}_{3} \mathrm{O}_{4}$ iron-oxide (magnetite) ferrofluids with different surfactants were sourced from FerroTec (US) and compared as follows: EMG 1200 - Fatty acid, EMG 1300 - Polymeric and EMG 1400 - Hydrophobic [1]. When the ferrofluid is heated, the carrier fluid evaporates and a sludge of solid particles and surfactant remains. When the ferrofluid is cooled, the carrier fluid condenses and ideally mixes with the particle sludge. The aim of this experiment was to demonstrate and visualise the mixing behaviour of the condensed carrier fluid with the ferrofluid particles. Hence, this paper presents preliminary experimental results on ferrofluid evaporation and condensation demonstrating the possibility of two-phase ferrofluid applications by comparing the effects a fatty acid, a polymeric and a hydrophobic-surfactant have oniron oxide nanoparticles in a n-Heptane carrier fluid. These preliminary results enable further investigation into powerful ferrofluid cooling systems capable of dissipating extreme thermal loads and reducing the cooling device size.

Thermal conductivity, evaporation and condensation has been extensively studied with solids and fluids providing sufficient theoretical and experimental evidence for most engineering applications. The proposed ferrofluid evaporation experiment takes place under constant thermal boundary conditions where the heat flow $Q$ [W] is defined as [10, 11]:

$$
Q=-k A \frac{\Delta T}{\Delta x}=\frac{\Delta U}{\Delta r}+\frac{W}{\Delta r}
$$

and where $k\left[W \cdot m^{-1} \cdot K^{-1}\right]$ is the thermal conductivity of the material, $A\left[m^{2}\right]$ the surface area, $\Delta T[K]$ the available temperature difference, $\Delta x[m]$ the thickness, $\Delta U[J]$ change in internal energy and $W[J]$ work done by the thermodynamic system. When maximising the heat flow in equation 1 , it is crucial to improve the thermal conductivity $k$ of the material. The effective thermal conductivity determining the heat transfer in a ferrofluid suspension $k_{\text {susp }}\left[W \cdot m^{-1} \cdot K^{-1}\right]$ is based in the thermal conductivity of the carrier fluid $k_{f l u i d}\left[W \cdot m^{-1} \cdot K^{-1}\right]$ and the thermal conductivity of the suspended ferromagnetic particles $k_{\text {solid }}\left[W \cdot m^{-1} \cdot K^{-1}\right]$, and is generally correlated by the following expression for a two component ferrofluid mixture as follows [5]:

$$
k_{\text {susp }}=k_{\text {liquid }} \frac{1+0.5\left(\frac{k_{\text {solid }}}{k_{\text {liquid }}}\right)-\Phi\left(1-\left(\frac{k_{\text {solid }}}{k_{\text {liquid }}}\right)\right.}{1+0.5\left(\frac{k_{\text {solid }}}{k_{\text {liquid }}}\right)+0.5 \Phi\left(1-\left(\frac{k_{\text {solid }}}{k_{\text {liquid }}}\right)\right.}
$$

where $\Phi[-]$ is the volume phase fraction of the solid. Assuming that the solid particles are coated in a surfactant and heated in series under uniaxial heating conditions, the thermal conductivity for the solid component in equation 2 is defined as [18]:

$$
\frac{1}{k_{\text {solid }}}=\frac{1}{k_{\text {surfactant }}}+\frac{1}{k_{\text {particles }}}
$$

with proportional components for particles content and surfactant in dry particles. Most common ferrofluids have solid phase fractions between $1-10 \%$ including the surfactant component. Hence, based on equation 2 the thermal conductivity of most ferrofluids is only slightly higher with the suspended particles than the thermal conductivity of the carrier fluid, and only moderately improves with increasing particle concentration, and overall does not improve the thermal conductivity of the fluid significantly $[7,9,16,17]$. According to equation 1 , in order to improve the heat transfer of a ferrofluid, evaporating the liquid carrier fluid requires a substantial amount of thermal energy to change from the liquid phase to the gas phase. The corresponding thermal evaporation enthalpy $\Delta H_{\text {evap }}[J]$ is defined as $[10]$ :

$$
\Delta H_{\text {evap }}=\Delta U_{\text {evap }}+W
$$

and the evaporation change in energy is $\Delta H_{\text {evap }}[J]$. Substituting equation 4 into equation 1 enables to maximise the heat flow with ferrofluids using thermal evaporation. For the proposed evaporation experiment, dry ferrite particles (Ferrotech - US) were disperse in n-Heptane at a concentration of $1 \%$ by weight and sonicated for 10 minutes [1]. The iron-oxide particles have an average particles size of $10 \mathrm{~nm}$ and a thermal conductivity of $2.4 \mathrm{~W}^{-1} \mathrm{~m}^{-1} \cdot K^{-1}$ [15].The surfactants (fatty acid-, polymeric- and hydrophobic) are initially assumed to have an approximate thermal conductivity of $1 \mathrm{~W} \cdot \mathrm{m}^{-1} \cdot K^{-1}[14]$. For the n-Heptane carrier fluid a thermal conductivity of $0.14 \mathrm{~W}^{-1} \mathrm{~m}^{-1} \cdot K^{-1}$ is assumed [4]. Essentially, the effective thermal conductivity increases linearly to the change in the weight phase 
fraction of the iron-oxide particles added [16]. Subsequently, the sonicated $1 \%$ ferrofluid suspension was transferred into a [2] $500 \mu \mathrm{m} \times 100 \mu \mathrm{m}$ square and $70 \mathrm{~mm}$ long sealed closed volume glass capillary.

\section{Results}

According to equation 2, the thermal conductivity was calculated for particle weight fractions between $1-10 \%$ for the EMG 1200, EMG 1300 and EMG 1400 ferrofluids. Calculation results are shown in Fig. 1. As it could be expected, the values increase linearly with the increase of ferrofluid concentration.

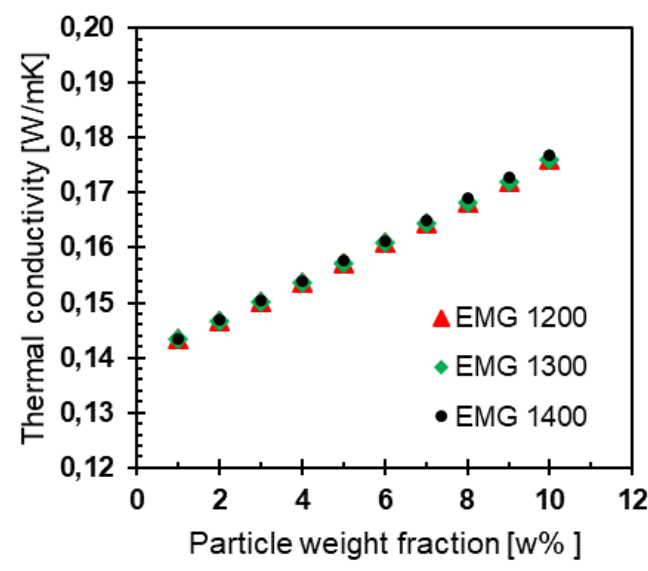

Figure 1. Calculated thermal conductivity for EMG 1200, EMG 1300 and EMG 1400 as a function of iron-oxide particle weight concentration in percent.

Table 1. Property of EMG 1200, EMG 1300 and EMG 1400 ferrofluids [3, 8, 23]

\begin{tabular}{|c|c|c|c|c|}
\hline Properties & unit & EMG 1200 & EMG 1300 & EMG 1400 \\
\hline Iron-oxide content in dry particles & {$[\%]$} & 70 & 70 & 80 \\
Particle weight phase fraction & {$[\%]$} & 1 & 1 & 1 \\
Calculated thermal conductivity & {$\left[\frac{W}{m \cdot K}\right]$} & 0.143 & 0.143 & 0.144 \\
Surfactant & {$[-]$} & Fatty acid & Polymeric & Hydrophobic \\
Surficant thermal conductivity & {$\left[\frac{W}{m \cdot K}\right]$} & 0.289 & 0.330 & 0.285 \\
\hline
\end{tabular}

Based on equation 2, Figure 1 shows a linear increase in calculated thermal conductivity for the three ferrofluids with only a slightly higher thermal conductivity of $0.144 \mathrm{~W} \cdot \mathrm{m}^{-1} \cdot \mathrm{K}^{-1}$ for EMG1400 compared to $0.143 \mathrm{~W} \cdot \mathrm{m}^{-1} \cdot \mathrm{K}^{-1}$ for EMG 1200 and EMG 1300 at 1\% of Iron-oxide particle weight phase fraction. These results are in good agreement with experimental measurements reporting thermal conductivity for iron-oxide ferrofluids with up to $25 \%$ particle weight fraction [6].

As can be seen from the properties of EMG 1200, EMG 1300 and EMG 1400 ferrofluids in Table 1, the slightly higher thermal conductivity with EMG 1400 stems from higher Iron-oxidecontent of $80 \%$ compared to $70 \%$ with EMG 1200 and EMG 1300. Due to the lack of information on the exact molecule structure of the surfactants employed, it is assumed that the fatty acid-, polymeric- and hydrophobic-surfactants have an identical thermal conductivity.

For the evaporation and condensation, the glass capillaries where filled with the EMG 1200, EMG 1300 and EMG 1400 ferrofluid and heated with a hot plate to $115^{\circ} \mathrm{C}$ together with a pure heptane filled capillary as reference.

Figure 2 shows from left (l) to right (r)the capillaries filled with the sonicated ferrofluid EMG 1200, ferrofluid EMG 1300, ferrofluid EMG 1400 and pure Heptane for reference. Figure 3 shows the capillaries heated to a temperature of $115^{\circ} \mathrm{C}$. At $115^{\circ} \mathrm{C}$, the Heptane carrier fluid has evaporated leaving a particle sludge along the capillary. Figure 4 shows the ferrofluid at room temperature after the Heptane carrier fluid condensed. According to Figure 4, the ferrofluid EMG 1200 with the fatty acid surfactant shows good dispersion and therefore good mixing after condensation. 


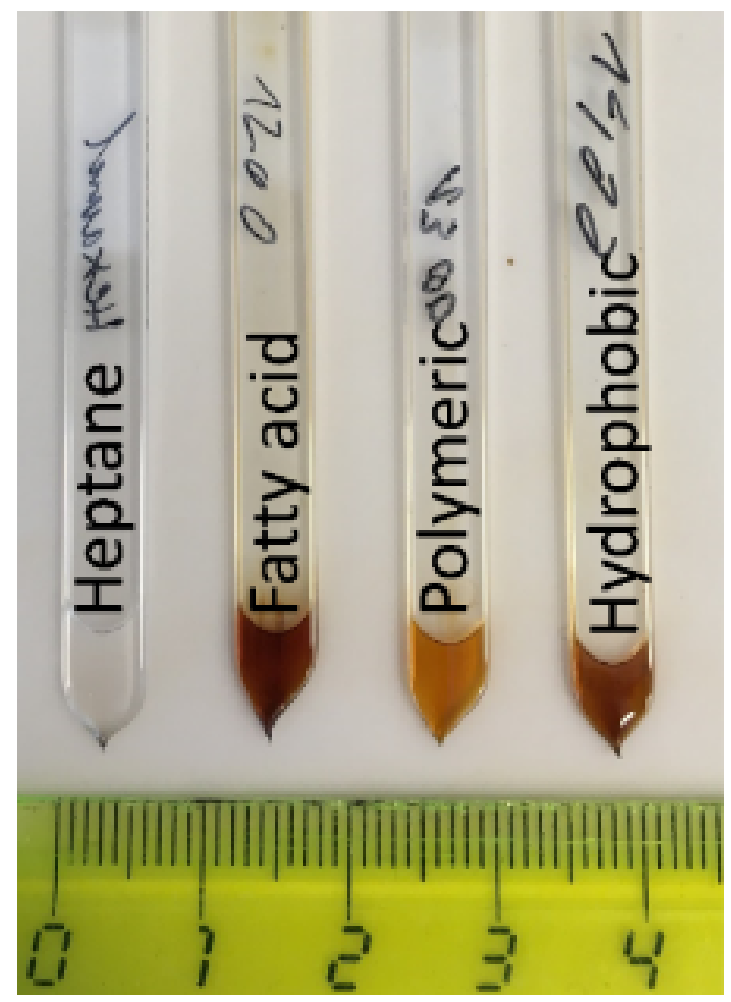

Figure 2. Ferrofluids photo before experiment

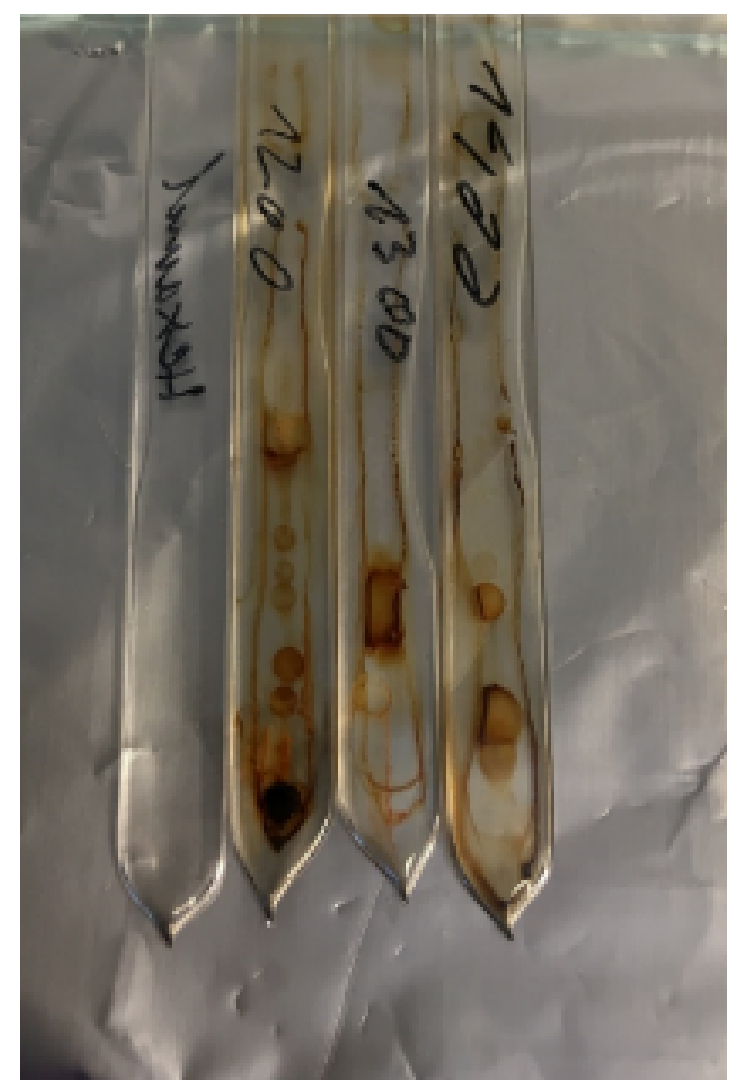

Figure 3. Ferrofluids photo at $115^{\circ} \mathrm{C}$ 


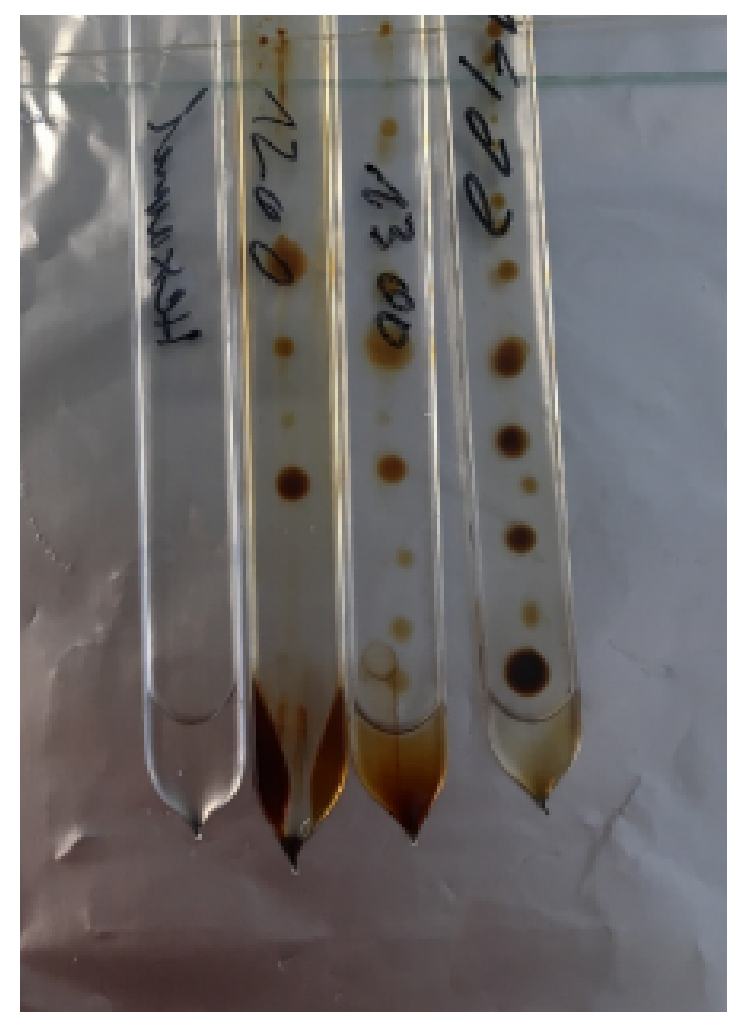

Figure 4. Ferrofluids photo after condensation at room temperature.

Compared to the EMG 1200, the ferrofluid EMG1300 with a polymeric surfactant and the condensed EMG 1400 with a hydrophobic surfactant shows adistinct separation between the heptane carrier fluid and the particle sludge compared to Figure 2. As an example, oleic acid is a fatty acid compound and is commonly used in iron-oxide nanoparticles creating a chelate bond with the iron atoms, which is stronger than a simple physisorption and subsequently survives higher temperatures [24]. For the demonstrated polymeric and hydrophobic surfactants in EMG 1300 and EMG 1400 aggregation took place during evaporation. If the surfactant molecules are weakly bonded to the particles, their desorption from the particles is already apparent at slightly elevated temperatures thus causing aggregation during evaporation.

\section{Conclusions}

The surfactants used in ferrofluids are crucial for the interactions between particles in fluids. The article examines various surfactants in terms of their cooperation with ferromagnetic iron oxide particles. The research showed the influence of various surfactants on the thermophysical properties of ferrofluid. With regard to thermal evaporation, the fatty acid surfactant shows dispersion after condensation, which indicates good mixing of the ferrofluid particles. In contrast to fatty acid, the polymeric and hydrophobic surfactant ferrofluids exhibit particle agglomeration and separation of condensate and particle sludge.

\section{References}

1. www.ferrofluid.ferrotec.com/technology.

2. Altan, C., Elkatmis, A., Yuksel, M., Aslan, N. \& Bucak, S. Enhancement of thermal conductivity upon application of magnetic field to Fe3O4 nanofluids. Journal of Applied Physics 110 (9 2011).

3. Andersson Trojer, M., Mohamed, A. \& Eastoe, J. A highly hydrophobic anionic surfactant at oil-water, water-polymer and oil-polymer interfaces: Implications for spreading coefficients, polymer interactions and microencapsulation via internal phase separation. Colloids and Surfaces A: Physicochemical and Engineering Aspects 436, 1048-1059. ISSN: 0927-7757 (2013). 
4. Assael, M. J. et al. Reference Correlation of the Thermal Conductivity of n-Heptane from the Triple Point to $600 \mathrm{~K}$ and up to $250 \mathrm{MPa}$. Journal of Physical and Chemical Reference 42 (2 2013).

5. Chabra, R. \& Richardson, J. Non-Newtonian flow in the process industries: fundamentals and engineering applications (Butterworth-Heinemann, 1999).

6. Fertman, V., Golovicher, L. \& Matusevich, N. Thermal conductivity of magnetite magnetic fluids. Journal of Magnetism and Magnetic Materials 65, 211-4 (2-3 1987).

7. Grzebielec, A., Rusowicz, A. \& Ruciński, A. Analysis of the performance of the rotary heat exchanger in the real ventilation systems in. 9th International Conference on Environmental Engineering, ICEE 2014 (Vilnius; Lithuania, 2014).

8. Heim, D., Mrowiec, A. \& Prałat, K. Zastosowanie metody "gorącej nici" do wyznaczania przewodności cieplnej płynnych kwasów organicznych. Inżynieria i Aparatura Chemiczna 49, 51-52 (1 2010).

9. Hong, T., Yang, H. S. \& Choi, C. J. Study of the enhanced thermal conductivity of Fe nanofluids. Journal of Applied Physics 97 (6 2005).

10. Incropera, F., Lavine, A., Bergman, T. \& DeWitt, D. Fundamentals of heat and mass transfer (Wiley, 2007).

11. Jaworski, M., Rusowicz, A. \& Grzebielec, A. Temperature stabilization in buildings by the use of heat/cold storage units with PCM integrated with the ventilation system. Inżynieria Bezpieczeństwa Obiektów Antropogenicznych 3, 31-37 (2019).

12. Kandlikar, S. et al. Heat transfer in microchannels - 2012 status and research needs. Journal of Heat Transfer $\mathbf{1 , 1 3 5}$ (9 2013).

13. Kosterec, M. et al. Analysis of Thermal Field in Mineral Transformer Oil Based Magnetic Fluids. Acta Physica Polonica 1,131, 937-9 (4 2017).

14. Lenin, R. \& Joy, P. Role of base fluid on the thermal conductivity of oleic acid coated magnetite nanofluids. Colloids and Surfaces A. Physicochemical and Engineering Aspects 529, 922-9 (2017).

15. Li, M. et al. Thermal Conductivity of Oxide Scale Thermally Grown on Iron Substrate Corrected by Temperaturedependent Interfacial Thermal Resistance in Laser Flash Measurement. ISIJ International 59, 398-403 (3 2019).

16. Owczarek, M. An experimental method for estimating the thermal diffusivity of building elements, depending on the resolution of temperature measurement. Modern Engineering, 28-33 (2019).

17. Owczarek, M. \& Baryłka, A. Determining the thermal diffusivity of the material based on the measurement of the temperature profile in the wall. Rynek energii 143, 63-69 (4 2019).

18. Pietrak, K. \& Wiśniewski, T. A review of models for effective thermal conductivity of composite materials. Journal of Power Technologies 23,95, 14-24 (1 2014).

19. Popplewell, J., Al-Qenaie, A., Charles, S., Moskowitz, R. \& Raj, K. Thermal conductivity measurements on ferrofluids. Colloid and Polymer Science 260, 333-8 (3 1982).

20. Raffa, P., Wever, D., Picchioni, F. \& Broekhuis, A. Polymeric surfactants: synthesis, properties, and links to applications. Chemical reviews 16,115, 8504-63 (16 2015).

21. Raj, K. \& Moskowitz, R. Commercial applications of ferrofluids. Journal of Magnetism and Magnetic Materials 1,185, 233-45 (1-3 1990).

22. Rosensweig, R. Fluid dynamics and science of magnetic liquids. InAdvances in electronics and electron physics. Academic Press 48, 103-199 (1979).

23. Shamsuri, A. A. \& Jamil, S. N. A. M. A Short Review on the Effect of Surfactants on the Mechanical-Thermal Properties of Polymer Nanocomposites. Applied Science 10 (2020).

24. Soares, P. et al. Effects of surfactants on the magnetic properties of iron oxide colloids. Journal of colloid and interface science 419, 46-51 (2014). 